\title{
Dip patch clamp currents suggest electrodiffusive transport of the polyelectrolyte DNA through lipid bilayers ${ }^{\text {is }}$
}

\author{
M. Spassova ${ }^{\text {a,b }}$, I. Tsoneva ${ }^{\text {b }}$, A.G. Petrov ${ }^{\text {a }}$, J.I. Petkova ${ }^{\text {a }}$, E. Neumann ${ }^{\text {c,* }}$ \\ a Institute of Solid State Physics, Bulgarian Academy of Sciences, 1784 Sofia, Bulgaria \\ ${ }^{\mathrm{b}}$ Central Laboratory of Biophysics, Bulgarian Academy of Sciences, 1113 Sofia, Bulgaria \\ ${ }^{c}$ Faculty of Chemistry, University of Bielefeld, POB 100131, D-33501 Bielefeld, Germany
}

Received 5 January 1994; accepted in revised form 12 July 94

\begin{abstract}
Planar lipid bilayers formed from monolayers of diphytanoyl lecithin (DPhL) were found to interact with plasmid DNA (5.6 kbp; $M_{\mathrm{r}}=3.7 \times 10^{6}$ ) leading to an increase in the conductance of the membrane. The association of DNA with a lipid bilayer greatly facilitates the transport of the small ions of the main salt $\mathrm{KCl}$. The appearance of long-lived current levels, for instance, of $27.6 \mathrm{pA}$ at $V_{\mathrm{m}}=+60 \mathrm{mV}$ membrane voltage, where the actual contact (adsorption) is electrophoretically enhanced, suggests a locally conductive DNA/lipid intcraction zone where parts of the DNA strand may be transiently inserted in the bilayer, leaving other parts of the DNA probably protruding out from the outer surface of the bilayer. At $V_{\mathrm{m}}=-60 \mathrm{mV}$, where DNA can be electrophoretically moved away from the membrane, the membrane current is practically zero. This current asymmetry is initially also observed at higher voltages, for instance at $200 \mathrm{mV}$. However, if the voltage sign $\left(V_{\mathrm{m}}=+200 \mathrm{mV}\right)$ is changed after a transient positive current $(\approx 15 \mathrm{pA})$ was observed, there is also now (at $V_{\mathrm{m}}=-200 \mathrm{mV}$ ) a finite negative current at the negative membrane voltage. Thus, it appears that at $V_{\mathrm{m}}=+200 \mathrm{mV}$ the adsorbed parts of the polyelectrolyte DNA are not only transiently inserted in, but actually also electrophoretically pulled through, the porous zones onto the other membrane side leaving the bilayer structure basically intact. These data provide direct electric evidence for the electrophoretic transport of a highly charged and hydrated macromolecule, probably together with the associated gegen-ions, through the thin hydrophobic film of the lipid bilayer.
\end{abstract}

Keywords: Patch clamp; Electrophoretic DNA transfer; Long-lived conductive state; Plasmid DNA; Diphytanoyl lecithin monolayers

\section{Introduction}

Manipulation of biological cells and cell tissue by electroporation techniques gains increasing importance for biophysics and cell biology in general and in biotechnology and medicine in particular [1-3]. The electroporation method is perhaps the most popular tool for

\footnotetext{
Dedicated to Professor Michel Mandel on the occasion of his retirement as Principal Editor of Biophysical Chemistry.

* Corresponding author.
}

the direct transfer of foreign genes (DNA) into cells [4].

Contrary to the many applications of membrane electroporation to transfect and transform eukaryotic and prokaryotic cells, the mechanism of electro-induced transfer of DNA through lipid/protein membranes and cell walls is not well understood. Since there is occasional DNA uptake by cells even in the absence of external electric fields, it is implicite that the enhanced DNA penetration through electroporated membrane 


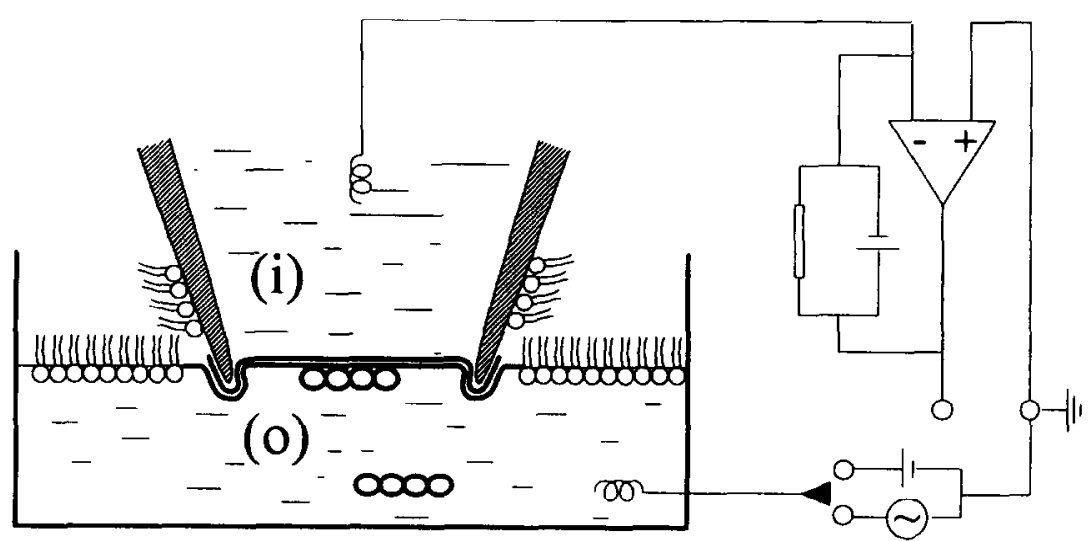

Fig. 1. Scheme of the experimental setup for the interaction of plasmid DNA (pDNA) with a lipid bilayer. The pipette is of thick-walled borosilicate glass of tip diameter $\varnothing=3( \pm 1) \mu \mathrm{m}$. The solutions inside (i) and outside (o) of the pipette are: $150 \mathrm{mM} \mathrm{KCl}, 1 \mathrm{mM} \mathrm{Tris} \cdot \mathrm{HCl}$, $\mathrm{pH} 7.2$ at $22^{\circ} \mathrm{C}$. The concentration of the plasmid DNA macromolecule $\left(M_{\mathrm{r}}=3.7 \times 10^{6}\right)$ in the outside solution is [pDNA] $=1 \mathrm{nM}$. The transmembrane voltage is given by $V_{m}=\phi(i)-\phi(0)$, where $\phi(i)$ and $\phi(0)$ are the electric potentials of the inside (i) and outside (o) of the pipette, respectively.

patches [4] involves both diffusion of adsorbed DNA as well as electrodiffusion of the polyelectrolyte DNA. Evidence is accumulating that indeed the electrophoretic properties of nucleic acids and proteins are important for the membrane transfer.

However, as recently discussed at length by Klenchin, the problem electrophoresis (or electrodiffusion) versus other transport mechanisms is not yet clarified [5]. Here we provide data [6] that are consistent with an electrophoretic transfer of DNA into, and through, a lipid bilayer using a patch clamp method [7]. The appearance of long-lived conductive states of the bilayer in the presence of DNA suggests lipid/DNA interactions in long-lived metastable pore-like structures. The asymmetry of the currents with respect to the signs of membrane voltage and the transience of the increase in the conductance at higher voltages indicate actual transfer of DNA through electroporated bilayers.

\section{Materials and methods}

The bacterial membrane lipid diphytanoyl lecithin (DPhL, $M_{\mathrm{r}}=846.3$; Avanti Polar Lipids, Birmingham, Alabama) is particularly suited for the preparation of bilayer membranes in the fluid state. The plasmid DNA, YEp $351(5.6 \mathrm{kbp})$ [7] was isolated and purified in supercoil form using the method of Maniatis et al. [8].

The scheme of the experimental set up for the electrical current-voltage studies is shown in Fig. 1. Planar lipid bilayers were prepared from $\mathrm{DPhL}$; bilayers of this lipid are highly fluid at temperatures $T \geqslant-120^{\circ} \mathrm{C}$. The electrolyte buffer conditions used were $150 \mathrm{mM}$ $\mathrm{KCl}, 1 \mathrm{mM}$ Tris $\cdot \mathrm{HCl}, \mathrm{pH} 7.2$ at $22^{\circ} \mathrm{C}$. The bilayer was formed at the tip of a patch pipette from lipid monolayer spread on an air/water interface by the methods of Corronado and Latorre [9] and Schuerholz and Schindler [10]. Petri dishes of $10 \mathrm{~cm}^{2}$ area filled with $5 \mathrm{ml}$ of the buffer were used and the lipid monolayers were formed by spreading $6 \mu$ l solution of $\mathrm{DPhL}$ in hexane, $[\mathrm{DPhL}]=3 \mathrm{mg} \mathrm{ml}^{-1}$, over the electrolyte surface [11].

The pipettes were pulled from thick-walled borosilicate glass (GC150-10, Clark Electronic Instruments) in two succcssive pulls by a vertical puller. When filled with the buffer, the pipettes had a resistance in the range of $3 \pm 2 \mathrm{M} \Omega$ which corresponds to a tip diameter $\varnothing=3 \pm 1 \mu \mathrm{m}$ [12]. The seal resistance of the bilayers was typically in the order of $10 \mathrm{G} \Omega$. Membrane voltage $\left(V_{\mathrm{m}}\right)$ by convention bears the sign of the electrode inside the pipette, thus positive voltage corresponds to cations flowing out of the pipette and anions into the pipette. Explicitely, $V_{m}$ is defined by:

$V_{\mathrm{m}}=\phi(\mathrm{o})-\phi(\mathrm{i})$

where $\phi(0)$ is the electric potential of the solution outside the pipette and $\phi(i)$ is that of the pipette interior. The DNA is added to the outside solution.

The transmembrane currents were recorded using a self-made patch clamp amplifier ( $1-3 \mathrm{kHz})$, with cur- 
rent and voltage output connected to an oscilloscope and to a two channel analog-digital converter in an IBM PC compatible computer. Triangle voltage pulses (ramps) were generated by a function generator; in case of a voltage clamp (DC) the patch clamp amplifier was used.

For data analysis the software package programs, PAT (gift of Dr. J. Dempster, University of Strathclyde, UK), ION and HUND (Ivan Bonev, Sofia, Bulgaria) were used. The current-voltage surface method [13] was applied to visualize the accumulated current responses to triangular voltage ramps.

The presumed interaction between DNA and lipid monolayers were measured by the surface pressure of lipid monolayers formed in the same petri dishes (Wilhelmy type surface tensiometer, Nima Technology Ltd, Model ST 9000). The output of the tensiometer was sampled and visualized as a function of time by an PC/ AT compatible computer. The lipid monolayer surface pressure $(\sigma)$ was varied by changing the amount of lipid and, in some cases, by brief aspiration of part of the spread monolayer. DPhL was spread from hexane solution, $[\mathrm{DPhL}]=0.8 \mathrm{mg} \mathrm{ml}^{-1}$; DNA solution was gently injected into the subphase (see Fig. 2).

\section{Results}

In Fig. 2 is seen that the addition of DNA to the buffer solution with a lipid monolayer of surface pressure $\sigma_{0} \approx 12 \mathrm{mN} \mathrm{m}^{-1}$ induces an increase $\Delta \sigma \approx 0.2 \mathrm{mN}$ $\mathrm{m}^{-1}$ followed by a gradual further increase to $\sigma \approx 14.5$ $\mathrm{mN} \mathrm{m}^{-1}$ (B). On the other hand, addition of DNA to the same buffer solution without a lipid monolayer does not lead to changes in the surface tension $\gamma$, remaining at $\gamma=\gamma_{0}-\sigma=\gamma_{0}=78 \mathrm{mN} \mathrm{m}^{-1}$ at $20^{\circ} \mathrm{C}$ (A). If the initial pressure of the monolayer was $\sigma_{0} \geqslant 25 \mathrm{mNm}^{-1}$, the addition of pDNA did not produce any changes of the monolayer surface pressure (data not shown). The double arrows illustrate the interaction of pDNA with the lipid head groups leading to a less dense lipid packing.

The current $(I) /$ voltage $\left(V_{\mathrm{m}}\right)$ surface profiles in Fig. 3 indicate that the current through the DPhL bilayer can appreciably fluctuate already in the absence of DNA (A). In some bilayer preparations the fluctuations are much smaller (by a factor of 10 ) than those shown here. In the presence of DNA there is a transient
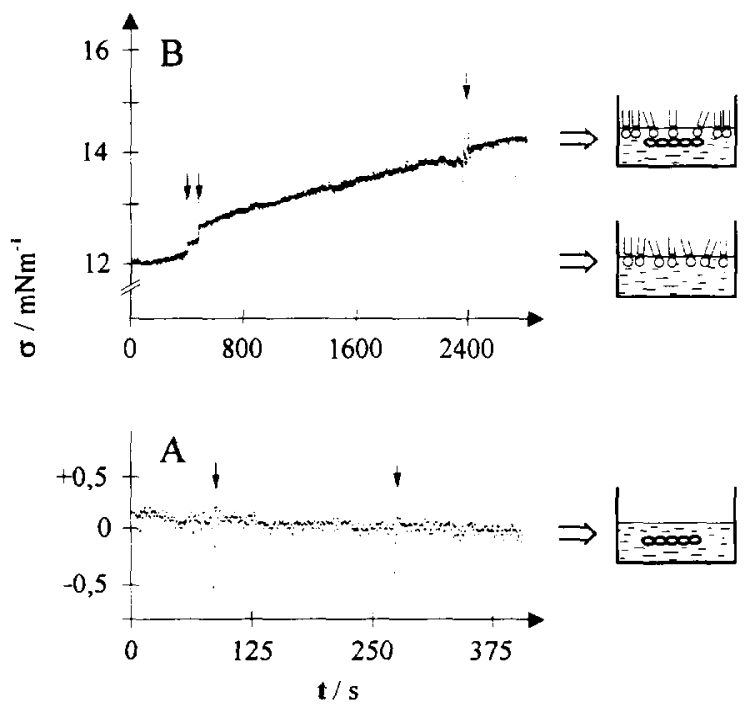

Fig. 2. Surface pressure $(\sigma)$ as a function of time $(t)$; (A) of a buffer solution ( $150 \mathrm{mM} \mathrm{KCl}, 1 \mathrm{mM}$ Tris $\cdot \mathrm{HCl}, \mathrm{pH}=7.2, T \approx 22^{\circ} \mathrm{C}$ ) and (B) of the same buffer solution to which the lipid $\mathrm{DPhL}$ was added such that the initial surface pressure is $\sigma_{0}=12 \mathrm{mN} \mathrm{m}^{-1}$. The arrows indicate successive additions of pDNA to yield the final concentrations: (A) $[\mathrm{pDNA}]=1$ and $2 \mathrm{nM}$ and (B), [pDNA] $=0.5,1$ and $2 \mathrm{nM}$, respectively. The double arrows point to schemes for the presumed interactions of pDNA with the lipid head groups leading to a less dense lipid packing as indicated by the increase in $\sigma$.

increase to a higher conductance level $G=3 \pm 0.6 \mathrm{nS}$ (B). This conductance value is transient; during the last 2-3 voltage ramps (out of a total of 9 ramps) the conductance drops back to the initial low value. It appears that the presence of DNA leads to a transient interaction with the bilayer involving either adsorption and desorption or actual transmembrane transport of DNA. The currents in the presence of DNA depend on the voltage polarity. The positive current $(I=90 \mathrm{pA})$ at the positive voltage $\left(V_{\mathrm{m}}=+30 \mathrm{mV}\right)$ is larger by about $10 \mathrm{pA}$ than the negative current $(I=-80 \mathrm{pA})$ at $V_{\mathrm{m}}=-30 \mathrm{mV}$. Thus, a current asymmetry is cleary indicated at this relatively low voltage.

The dependence of the current on the voltage polarity in the presence of DNA is more pronounced, and it is thus easier recognized, at the DC conditions of fixed higher voltages. Fig. 4 shows that only in the presence of DNA and only at the positive voltage $\left(V_{\mathrm{m}}=+60\right.$ $\mathrm{mV}$ ), i.e. negative electric potential at the membrane side of DNA addition and positive potential on the other membrane side, favouring (electrophoretic) adsorption of DNA at the $\phi(0)$ (Fig. 1), there is an apparently 


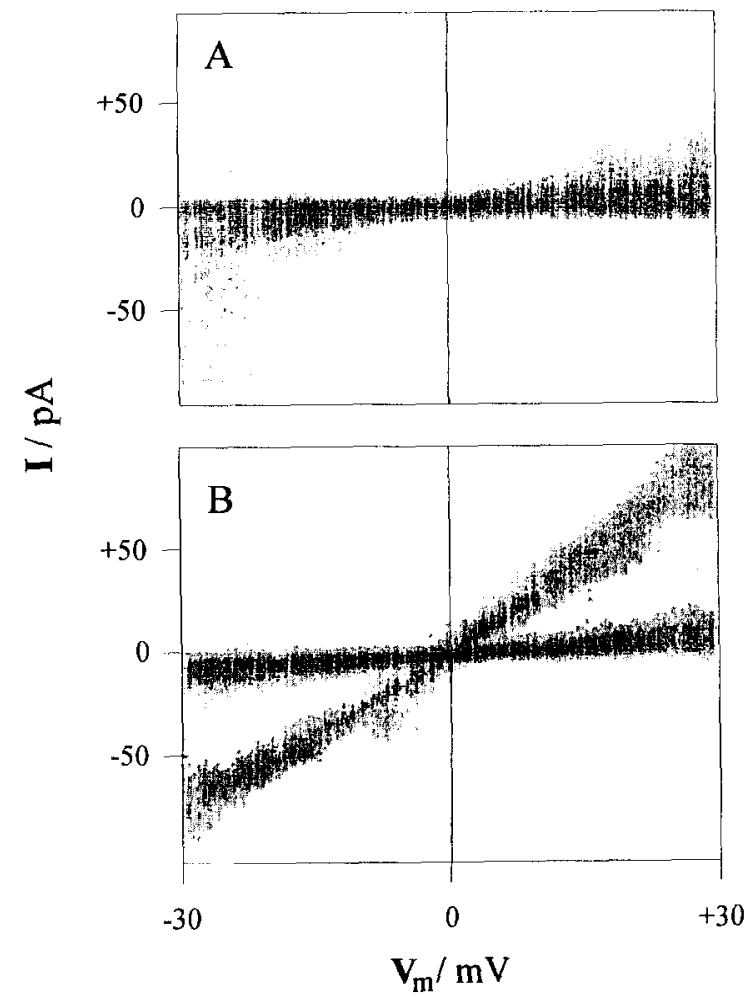

Fig. 3. Current $(I)$-voltage $\left(V_{\mathrm{m}}\right)$ surface profile of $(\mathrm{A})$ a pure $\mathrm{DPhL}$ bilaycr and of $(B)$ the samc bilayer in the presence of DNA; [pDNA] $=1 \mathrm{nM}$, in the outside solution $(150 \mathrm{mM} \mathrm{KCl}, 1 \mathrm{mM}$ Tris $\cdot \mathrm{HCl}, \mathrm{pH} 7.2), T=22^{\circ} \mathrm{C}$ : The pipette solution is the same buffer, but without DNA. The voltage was changed continuously in a ramp between $-30 \mathrm{mV}$ and $+30 \mathrm{mV}$ within $20 \mathrm{~s}$ (9 ramps within 180 s). With DNA (B), the conductance $G=I / V_{\mathrm{m}}$ transiently increases to $3 \pm 0.6 \mathrm{nS}$ and then during the last two ramps decreases to the initial low value.

long-lived increase in the membrane current. The histogram of the current traces indicates in this example a major current level of $I=27.6 \mathrm{pA}$. At $V_{\mathrm{m}}=-60 \mathrm{mV}$ where electrophoretic desorption of DNA from the membrane is favoured, the current is practically zero (data not shown).

Some bilayer preparations are such that even at $V_{\mathrm{m}}=200 \mathrm{mV}$ there are only minor current fluctuations around $I=0$. In Fig. 5 the current records of two successive DC-voltage polarities show that there are transient current increases also at the negative voltage clamp provided that $V_{\mathrm{m}}=-200 \mathrm{mV}$ was applied after the previous positive voltage $\left(V_{\mathrm{m}}=+200 \mathrm{mV}\right)$ and if the pDNA was originally in the outside solution of previously negative potential (Fig. 1). It is apparent that the bilayer exhibits local, long-lived open states of current intensity levels up to $15 \mathrm{pA}$ (B). At $V_{\mathrm{m}}=-200$ $\mathrm{mV}$ the histogram indicates a smooth distribution of current levels between 0 and $-10 \mathrm{pA}(\mathrm{C})$.

\section{Discussion}

Lipid bilayers of liposomes are reported to change the secondary structure of adsorbed DNA [14]. The changes in the surface pressure of a lipid monolayer, caused by DNA in the aqueous phase (Fig. 2) suggests that the DNA interacts with the lipid head groups. The interaction is enhanced by $\mathrm{Ca}^{2+}$, probably by bridging lipid head groups with the phosphate residucs of DNA. The lipids interacting with DNA in the air/water interface apparently repel each other more than in the absence of adsorbed DNA. In the interfacial DNA/lipid complex there is a larger distance between the lipids and this causes an increase in the surface pressure, which is dependent on DNA and on $\mathrm{Ca}^{2+}$ concentrations. At $[\mathrm{DNA}]=2 \mathrm{nM}$ and at a surface area of 10 $\mathrm{cm}^{2}$ (Petri dish) the time constant for the DNA induced change $\Delta \sigma \approx 1.5 \mathrm{mN} \mathrm{m}^{-1}$ is $\Delta t_{\mathrm{D}} \approx 30 \mathrm{~min}$ (Fig. 2). The mean distance $\bar{d}$ from which the DNA is diffusing to the lipid surface is estimated from the Einstein relationship:

$$
\left\langle d^{2}\right\rangle=6 D \Delta t_{\mathrm{D}}
$$

Since the diffusion coefficient of DNA is $D \approx 2 \times 10^{-8}$ $\mathrm{cm}^{2} \mathrm{~s}^{-1}$, we obtain $\bar{d}=\left\langle d^{2}\right\rangle^{1 / 2} \approx 1.5 \times 10^{-2} \mathrm{~cm}$, which is a physically acceptable value.

On the same line, DNA/lipid head group interactions are suggested to be the origin for the conductance increase of a lipid bilayer in the presence of DNA (Fig. 3 ). The transience of the conductance increase to $3 \mathrm{nS}$, lasting about $90 \mathrm{~s}$, may be caused by the adsorption and desorption of the DNA from the bilaycr. But the larger current $(I=90 \mathrm{pA})$ at $V_{\mathrm{m}}=+30 \mathrm{mV}$ compared with that $(I=-80 \mathrm{pA})$ at $V_{\mathrm{m}}=-30 \mathrm{mV}$ may also be caused by actual transport of the anionic polyelectrolyte DNA through the lipid bilayer area, to which the DNA was previously adsorbed. The positive voltage, referring to a negative electric potential on the side of DNA addition and a positive potential on the other membrane side, provides an electric potential drop for the DNA transport.

In any case, DNA appears to facilitate the transport of small ions such as those of the major salt $\mathrm{KCl}$ through 

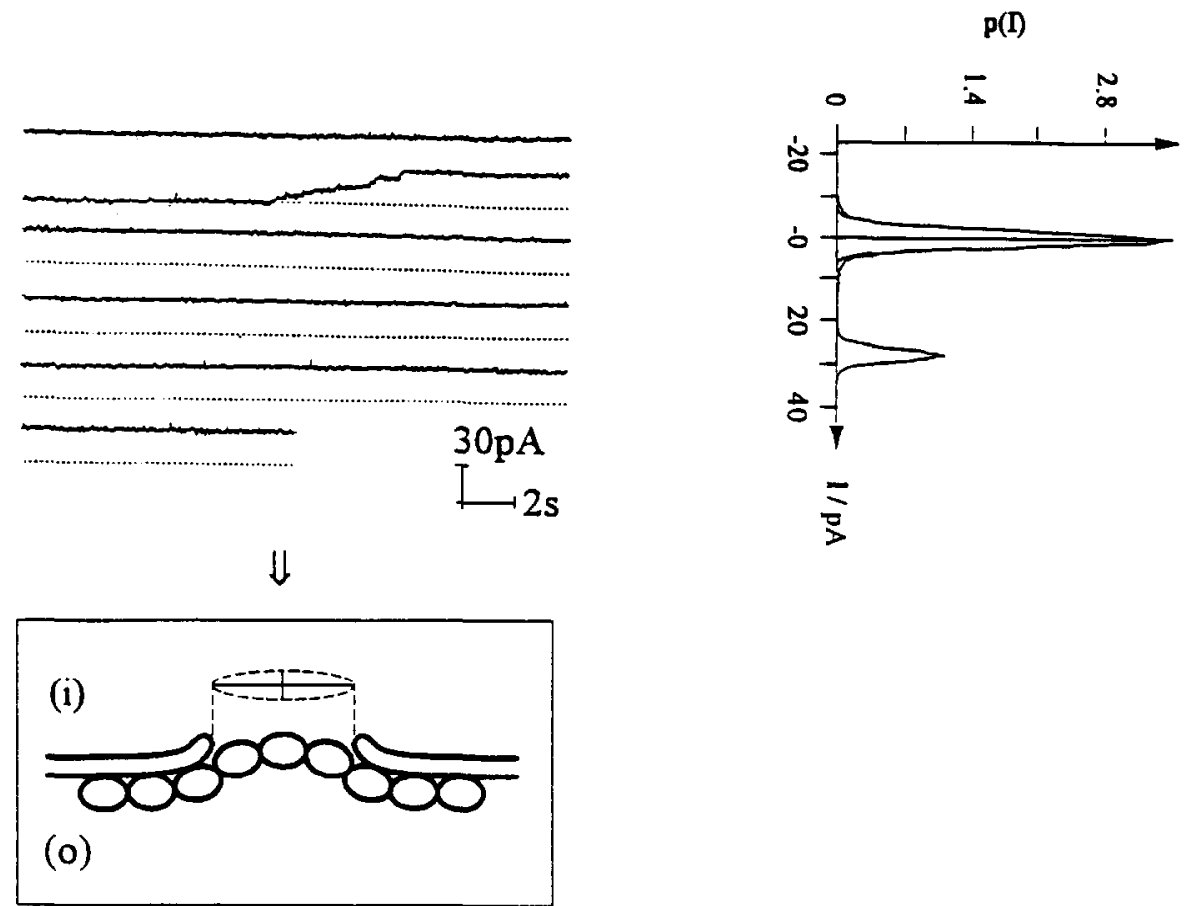

Fig. 4. Currents $(I)$ as a function of time through a pure DPhL bilayer at $\mathrm{V}_{\mathrm{m}}=+60 \mathrm{mV}$ and where pDNA was added to the outside solution $([\mathrm{pDNA}]=1 \mathrm{nM})$; the I trace refers to the initial section of $115 \mathrm{~s}$. Buffer conditions are as in Fig. 3. The long-lived increase in current occurs in the presence of DNA and only if the DNA is at the site of negative electric potential $(\phi(0))$, here at $V_{\mathrm{m}}=+60 \mathrm{mV}$. The current probability density $p(I)$ in units of \% time per $1.95 \mathrm{pA}$ is given as a function of $I$ for a total current record of $400 \mathrm{~s}$ (histogram). The double arrow points to the scheme for the presumed position of adsorbed pDNA in an elongated porous patch at $V_{m}=+60 \mathrm{mV}$, suggested for the appearance of the long-lived current level of $I=27.6 \mathrm{pA}$.

bilayer patches (elongated pores) interacting with parts of DNA. The increase of the current to $I=90 \mathrm{pA}$ at $V_{\mathrm{m}}=+30 \mathrm{mV}$ lasts about $2 \mathrm{~s}$. The charge $Q$ transported within $\Delta t=2 \mathrm{~s}$ is given by $Q=I \Delta t=0.18 \mathrm{nC}$. The charge $\mathrm{Q}_{\mathrm{DNA}}$ carried by one DNA molecule with $m=2 \times 5.6 \times 10^{3}$ (anionic) phosphate groups is given by

$Q_{\mathrm{DNA}}=2 m e_{0} f$,

where $f \approx 0.4$ is the reduction factor due to counterion screening in the relative motion of the cations and the polyanion [15], $e_{0}=1.6 \times 10^{-19} \mathrm{C}$ is the elementary charge and the factor 2 refers to the contribution of both cations and the polyanion. Here $Q_{\mathrm{DNA}} \approx 1.4 \times 10^{-6} \mathrm{nC}$. Since $Q_{\mathrm{DNA}} \ll Q$, the current increase is certainly induced by the DNA/bilayer contact but the current itself is mainly carried by other ions $(\mathrm{KCl})$ than those of the DNA $\left(\mathrm{K}^{+}\right)_{\mathrm{m}}$ salt.

The slight asymmetry of the DNA-induced current increase, already indicated in the current-voltage pro- file (Fig. 3), where the membrane voltages alternatingly change sign, is confirmed by the current traces at a constant voltage (Figs. 4 and 5). The current increase from $I=0$ to $I>0$ occurs only in the presence of DNA (in the solution outside the pipette) and at $V_{\mathrm{m}}>0$, i.e. if the inside of the pipette is at positive electric potential $\phi(i)$. For $V_{\mathrm{m}}=+60 \mathrm{mV}$ apparently discrete current levels occur. In the example given in Fig. 4 there is a long-lived major current level of $I=27.6 \mathrm{pA}$. The interaction of DNA adsorbed to the outside surface of the bilayer seems to stabilize larger partially porous patches. For instance, the middle part of the DNA may remain within an elongated electropore whereas the end pieces may still stick out of the outside surface of the bilayer; see the insert in Fig. 4.

There are finitc (ncgative) currents at a ncgative voltage provided the system had been exposed at first to a positive voltage (Fig. 5), i.e. the DNA is at the side of negative electric potential. If, at a positive voltage, the transient positive current is induced by a DNA 
A

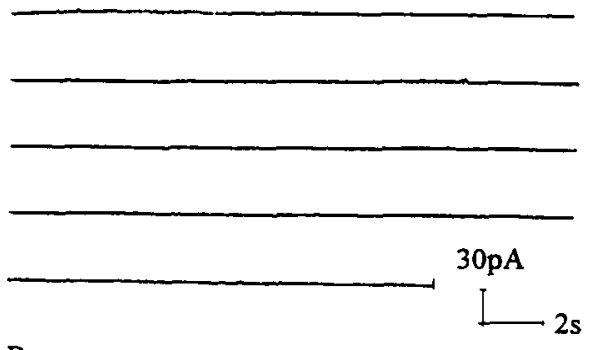

B
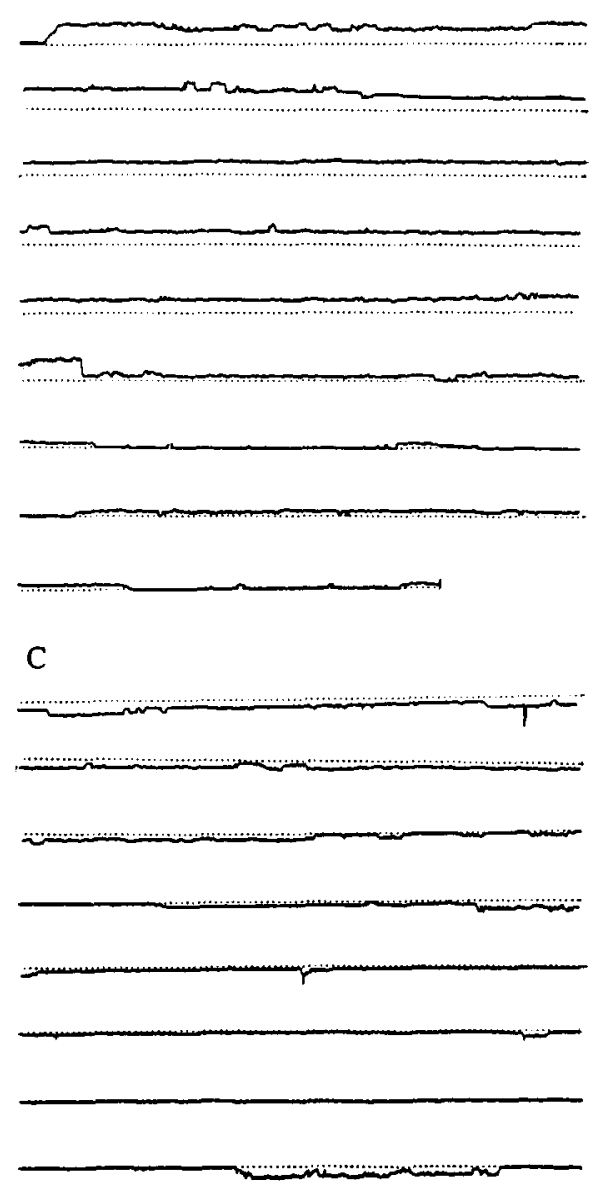

p (I)
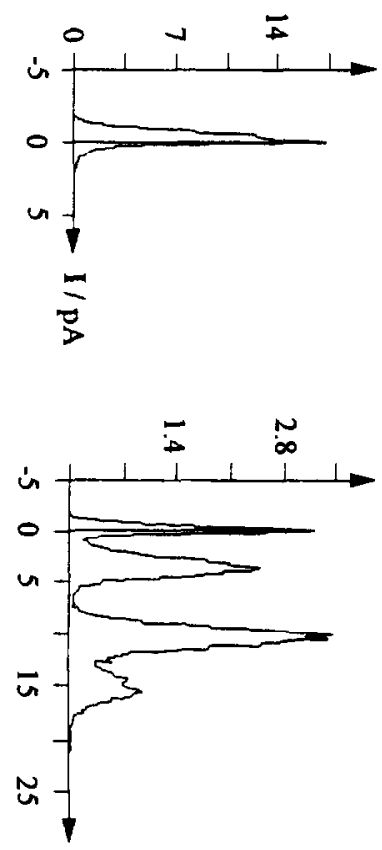

Fig. 5. Current intensity $(I)$ as a function of time at constant transmembrane voltage. (A) $V_{\mathrm{m}}=+200 \mathrm{mV}$, pure DPhL bilayer; $I=0$; (B) $V_{\mathrm{m}}=+200 \mathrm{mV}$ followed by (C) $V_{\mathrm{m}}=-200 \mathrm{mV}$, same bilayer exposed to pDNA added to the outside solution; [pDNA] $=1 \mathrm{nM}$. The current histogram in the presence of pDNA for trace (B) exhibits, in this example, at least three different current levels of higher probability: 4 pA, 11 $\mathrm{pA}$ and $15 \mathrm{pA}$. The histogram (A) refers to a record of $100 \mathrm{~s}$, those of (B) and (C) refer to records of $180 \mathrm{~s}$.

molecule migrating through an electroporated bilayer patch, the polyanion has changed the position from the outside to the inside surface by electrodiffusion toward the side of positive potential. Once DNA is at the inside surface, in the range of $\phi(i)$, see Fig. 1, a switch to a negative transmembrane voltage provides the potential drop for a return to the outside, concomitant with negative membrane currents. Therefore the change in cur- 
rent sign upon change in voltage sign and the transience of the currents are consistent with an actual transport of DNA across electroporated bilayers.

The interaction of the DNA with the membrane may be described in terms of small electropores percolated [16] along the adsorbed DNA to yield an elongated zone through which the small ions can pass. If the conductance $G(\mathrm{DNA})=27.6 \mathrm{pA} / 0.06 \mathrm{~V}=0.46 \mathrm{nS}$ (Fig. 4) would be caused by a (DNA-free) circular pore of radius $r_{\mathrm{p}}$, we may apply [17]:

$G=\lambda_{0} \pi r_{\mathrm{p}}^{2} /\left(d+\pi \frac{1}{2} r_{\mathrm{p}}\right)$

where $\lambda_{0}=1.8 \times 10^{-2} \mathrm{~S} \mathrm{~cm}^{-1}$ is the conductivity of the buffer solution at $22^{\circ} \mathrm{C}$ (Section 2) and $d=5 \mathrm{~nm}$ is the thickness of the bilayer. From Eq. (4) we obtain $r_{\mathrm{p}} \approx 0.7 \mathrm{~nm}$. Therefore, the actually free part of the bilayers zone interacting with DNA is $A=\pi r_{\mathrm{p}}^{2}=1.54$ $\mathrm{nm}^{2}$, which is rather small. The value of $r_{\mathrm{p}}$ is in the order of $0.5-1 \mathrm{~nm}$ estimated for hydrophilic pores [18].

On the other hand, if we assume that at higher voltages DNA migrates freely through a large electropore, the minimum time $\Delta t$ for passing the pore with the drift velocity $\boldsymbol{v}$ is given by

$\Delta t=\frac{l_{\mathrm{DNA}}}{|\boldsymbol{v}|}=\frac{l_{\mathrm{DNA}}}{u\left|\boldsymbol{E}_{\mathrm{eff}}\right|}$,

where $l_{\text {DNA }}$ is the effective length of a stretched supercoiled DNA, $u$ is the electrophoretic mobility of DNA and $E_{\text {eff }}$ is the field strength vector.

If the supercoiled pDNA is adsorbed on a flat surface, the chain may be approximated by $n$ circular loops of diameter $2 r$. The effective length $l_{\mathrm{DNA}}$ of this chain of loops is given by:

$l_{\mathrm{DNA}}=n 2 r$.

On the other hand, the contour length $L_{\mathrm{DNA}}$ of the double helix chain of $x$ base pairs (bp) is given by $L_{\mathrm{DNA}}=x \mathrm{bp} \cdot 0.34 \mathrm{~nm} / \mathrm{bp}$. Since the circumference of one loop is $2 r \pi$, we obtain

$L_{\mathrm{DNA}}=n 2 r \pi$.

Hence we may readily estimate the effective length from the contour length by

$l_{\mathrm{DNA}} \approx L_{\mathrm{DNA}} / \pi$.

For the pDNA of $5.6 \mathrm{kbp}$ we obtain $L_{\mathrm{DNA}}=1.9 \mu \mathrm{m}$ and $l_{\mathrm{DNA}} \approx 0.61 \mu \mathrm{m}$.
For the pDNA used here the numerical value of the mobility can be estimated from the data in ref. [19] by extrapolation to gel concentration zero: $u \approx 1.5 \times 10^{-4}$ $\mathrm{cm}^{2} \mathrm{~V}^{-1} \mathrm{~s}^{-1}$. The position of the electrodes in our experimental setup is such that $E_{\text {eff }}=0.2 \mathrm{~V} \mathrm{~cm}{ }^{1}$. Substitution yields $\Delta t \approx 2 \mathrm{~s}$. The observed current traces at $V_{\mathrm{m}}=0.2$ V last about $100 \mathrm{~s}$ (Fig. 5). These quantitative estimates suggest that it is unlikely that the long lasting currents are due to large pores through which DNA electrodiffuses freely.

In summary, the main result is that there are finite channel-like currents only if the DNA is at the negative potential side of the bilayer. All estimates are consistent with the interpretation that the adsorbed DNA is inserted in, and pulled through, an electropored bilayer zone which during the transport process interacts with the DNA, but that the bilayer as such basically remains intact.

\section{Acknowledgements}

We thank Professor P.N.R. Usherwood for support and PD Dr. Th. Schürholz for constructive criticism. We gratefully acknowledge the financial support from the Bulgarian National Fund for Scientific Studies, Grants N-K31, F19 and the Deutsche Forschungsgemeinschaft (DFG 227/9-1). I.T. and E.N. thank the European Community for the grant 739 of the Human Mobility Program.

\section{References}

[1] D.C. Chang, B.M. Chassy, J.A. Saunders and A.E. Sowers, eds., Guide to electroporation and electrofusion (Academic Press, New York, 1992) p. 581.

[2] E. Neumann, in: Electroporation and electrofusion in cell biology, eds. E. Neumann, A.E. Sowers and C.A. Jordan (Plenum Press, New York, 1989) pp. 61-82.

[3] E. Neumann, Bioelectrochem. Bioenerg. 28 (1992) 247-267.

[4] E. Neumann, M. Schaefer-Ridder, Y. Wang and H.P. Hofschneider, FMBO J. 1 (1982) 841-845.

[5] V.A. Klenchin, Biol. Mem. 7 (1994) 1-16.

[6] M. Spassova, M.Sc. Thesis, Lomonosov Moscow State University (1993).

[7] J.E. Hill, A. Myers, T.J. Koerner and A. Tzagoloff, Yeast 2 (1986) 163-167.

[8] T. Maniatis, E.F. Fritsch and J. Sambrook, Molecular cloning: A laboratory manual (Cold Spring Harbor Laboratory, Cold Spring Harbor, 1982). 
[9] R. Corronado and R. Latorre, Biophys. J. 43 (1983) 231-236.

[10] T. Schuerholz and H. Schindler, FEBS Letters 152 (1983) 187-190.

[11] A.G. Petrov, R.L. Ramsey, G.A. Codd and P.N.R. Usherwood, Eur. Biophys. J. 20 (1991) 17-29.

[12] B. Sakmann and E. Neher, in: Single-channel recordings, eds. B. Sakmann, E. Neher (Plenum Press, New York, 1983) p. 37-51.

[13] M.S.P. Sansom and I.R. Mellor, J. Theoret. Biol. 114 (1990) 213-223.
[14] V.G. Budker, A.A. Godovikov, L.P. Naumova and I.A. Slepneva, Nucl. Acids Res. 8 (1980) 2499-2515.

[15] A. Katchalsky, Pure Appl. Chem. 26 (1971) 327-373.

[16] I.P. Sugar and E. Neumann, Biophys. Chem. 19 (1984) 211225.

[17] B. Hille, Ionic channels of excitable membranes (Sinauer, Sunderland Mass, 1984)

[18] R.W. Glaser, S.L. Leikin, L.V. Chernomordik, V.F. Pastushenko and A.I. Sokirko, Biochim. Biophys. Acta 940 (1988) 275-287.

[19] H. Hervet and C.P. Bean, Biopolymers 26 (1987) 727-742. 